\title{
Microleakage and Marginal Integrity of Direct and Indirect Composite Resin Restorations in MOD Cavities After Thermo- Mechanical Loading
}

\author{
Ayse Asli Senol ${ }^{1}$, Pinar Yilmaz Atali ${ }^{1}$, Erkut Kahramanoglu² \\ ${ }^{1}$ Department of Restorative Dentistry, Faculty of Dentistry, Marmara University, Istanbul, Turkey \\ ${ }^{2}$ Department of Prosthodontics, Faculty of Dentistry, Marmara University, Istanbul, Turkey \\ Correspondence Author: Ayse Asli Senol \\ E-mail: asli.tuncer@marmara.edu.tr
}

Received: $17.02 .2021 \quad$ Accepted: 10.05 .2021

\begin{abstract}
Objective: The aim of this in vitro study is to compare the microleakage of mesial-occlusal-distal (MOD) composite resin restorations made by using CAD/CAM block and methacrylate/ormocer-based direct resin composites after thermo-mechanical loading.

Methods: Standard 40 noncarious human third mandibular molars were selected for the study. Standardized MOD $(3 \times 4 \times 2 \mathrm{~mm})$ cavities were prepared on the mesial and distal sides. The gingival margin was placed above the cementoenamel junction (CEJ) on the mesial side and below the CEJ on the distal side. The prepared samples were divided into three experimental groups [indirect group-GrandioBlock (GB), directmethacrylate group-TetricN-Ceram+TetricN-Flow (T+TF), direct-ormocer group-Admira Fusion+Admira Fusion Flow (A+AF)] and control group [direct-methacrylate group-GrandioSo+GrandioSoFlow (G+GF)] (n=10). After finishing restorations samples were subjected to $50 \mathrm{~N}$ to 240.000 thermo-mechanical cycles $\left(5-55^{\circ} \mathrm{C}\right.$, for $\left.60 \mathrm{sec}\right)$ and kept in $0.2 \%$ methylene blue. Samples sectioned longitudinally in the mesiodistal direction with a precision cutting device were examined under stereomicroscope at X8 and X25 and microleakage values were scored. In the evaluation of the data, descriptive statistical methods as well as the chi-square test was used for the comparison of qualitative data.

Results: No significant difference was found among the coronal and gingival-enamel microleakage distributions of the groups ( $p>0.05)$. A statistically significant difference was observed among the gingival-cementum microleakage distributions of the groups $(p=0.003)$. The distribution of gingival-cement microleakage with the no dye penetration score in the T+TF group was found to be statistically significantly lower than the G+GF and GB groups ( $p=0.010, p=0.001)$.

Conclusion: Under the limitation of this in vitro study; restoring MOD cavities using different matrix structures of the composites could not eliminate the leakage at the gingival seat under CEJ.
\end{abstract}

Keywords: CAD/CAM, chewing simulator, microleakage, ormocer, resin composite.

\section{INTRODUCTION}

In today's dentistry practice, resin composites are among the most preferred materials in the treatment of posterior teeth. Resin-based composite materials, which are developed day by day, exhibit acceptable aesthetic, physical, and mechanical properties (1-3). Composite materials have many advantages, as well as disadvantages. One of the most important of these disadvantages is polymerization shrinkage and the resulting microleakage. When the polymerization shrinkage exceeds the bonding strength between the restorative material and dental tissues; microleakage, plaque accumulation, post-operative sensitivity, bacterial penetration, pulpal inflammation, secondary caries, and fractures in the connective surface areas may occur due to the formation of micro-gaps between the restoration and dental tissue $(1,2)$. Polymerization shrinkage varies depending on the adhesive system used and the method of application, the intensity and mode of the light device used, the use of composite technology with ceramic technology, and the use of a flowable composite or liner in the cavity (4). Flowable composite resins are used in restorative dentistry applications to prevent polymerization shrinkage and to create a stress-breaking barrier under conventional composites. The ease of application and viscosity of flowable composites expand the indication of flowable composites in practical applications (5).

With the advances in the filling, matrix structure, and application techniques of composite resins, it is aimed to make more successful restorations. Ormocers are organically modified ceramic materials with high biocompatibility and less polymerization shrinkage. Unlike traditional polymers, the first produced ormocers; are obtained by adding monomers such as bisphenol-A (Bis-GMA), 
glycyldimethacrylate, hydroxylethyl methacrylate (HEMA), triethylene glycol dimethacrylate (TEGDMA) and urethane dimethacrylate (UDMA) and various inorganic fillers to the main structure consisting of Si-O-Si network consisting of inorganic-organic copolymers. The filler content consists of special glass, ceramic, and a high amount of silica (6). Innovative modifications of ormocer-based composites have been developed over time.

With the indirect application of composite restorations, ideal occlusal morphology, ideal approximal contact, ideal polished surface, and reduction in polymerization shrinkage, can be obtained $(7,8)$. However, incompatibility in inlay restorations can often be observed in the gingival margins (9). It can be thought that there is more microleakage in the gingival margin than the occlusal margin, depending on the problems that occur during impression and laboratory procedures. This problem can be eliminated with CAD/CAM systems. Due to the indirect application, the residual monomer amount decreases, thus properties such as aesthetics, optics, color stability, homogeneity, and fluorescence are obtained. It is thought that polymerization shrinkage in the application of indirect restorations will be limited to the adhesive cement and thus minimized (9-12).

Thermo-mechanical chewing simulators have been developed to mimic the stresses that occur in contact with the against tooth during chewing and to evaluate the effects of intraoral temperature changes and mechanical conditions on restorations (13). It is thought that the results obtained by comparing restorative materials with different thermal and mechanical properties will guide the selection of restorative materials in clinical applications.

This study was planned due to the limited literature data comparing the indirect restorative material Grandio Block with methacrylate and ormocer-based composite materials in terms of microleakage. The following null hypotheses were tested; 1 ) Composite restoration technique (direct vs. indirect) will not affect the microleakage values of the restorations. 2) Different types of matrix structure (ormocer vs. methacrylate) will not affect the microleakage values of the restorations.

\section{METHODS}

This study was approved by the ethic committee of Marmara University, Faculty of Dentistry in Istanbul, Turkey (Protocol number 2019-286).

The number of samples was determined based on power analysis. The minimum sample size required to detect a significance difference using this test should be at least 10 in each group, (60 in total), considering type I error (alfa) of 0.05 , power (1-beta) of 0.99 , and effect size of 1.623.

\subsection{Providence of Samples for Preparation}

In our study, 40 extracted sound mandibular molar teeth with similar dimensions were used. The teeth extracted within 6 months that provide these criteria were kept in an isotonic saline solution containing $0.1 \%$ thymol until the experimental stage. The residues on the teeth were cleaned with an ultrasonic device. A rubber bur and fluoride-free paste were then used to remove stains and debris. For preparation, the teeth were fixed in the pools of the chewing simulator using self-cure acrylic resin (Imicryl, Konya, Turkey).

\subsection{Preparation of the Samples}

According to the restoration method standard MOD cavities were prepared by a single researcher with round and inversely tapered diamond burs (Adia, Turkey) on all teeth. Standard MOD cavities preparations were approximately $3.0 \mathrm{~mm}$ in width buccolingually, $2.0 \mathrm{~mm}$ in axial depth, and $4.0 \mathrm{~mm}$ in gingival depth (Figure 1). The samples were randomly divided into 4 groups ( $n=$ 10) (Table 1). In the preparation of thirty molar teeth to be restored with the direct method, the cavity wall was prepared parallel to each other, with the width of the gingival cavity greater than the occlusal cavity width. A periodontal probe was used for millimetric measurement of cavity borders. In the preparation of ten molar teeth to be restored with indirect restorations, round corners were created within the cavity at an angle of $6-8^{\circ}$ between the cavity base and the side walls in accordance with the entrance path of the restoration. 
Table 1. Materials and Equipment Used in Indirect and Direct Restorations of Samples

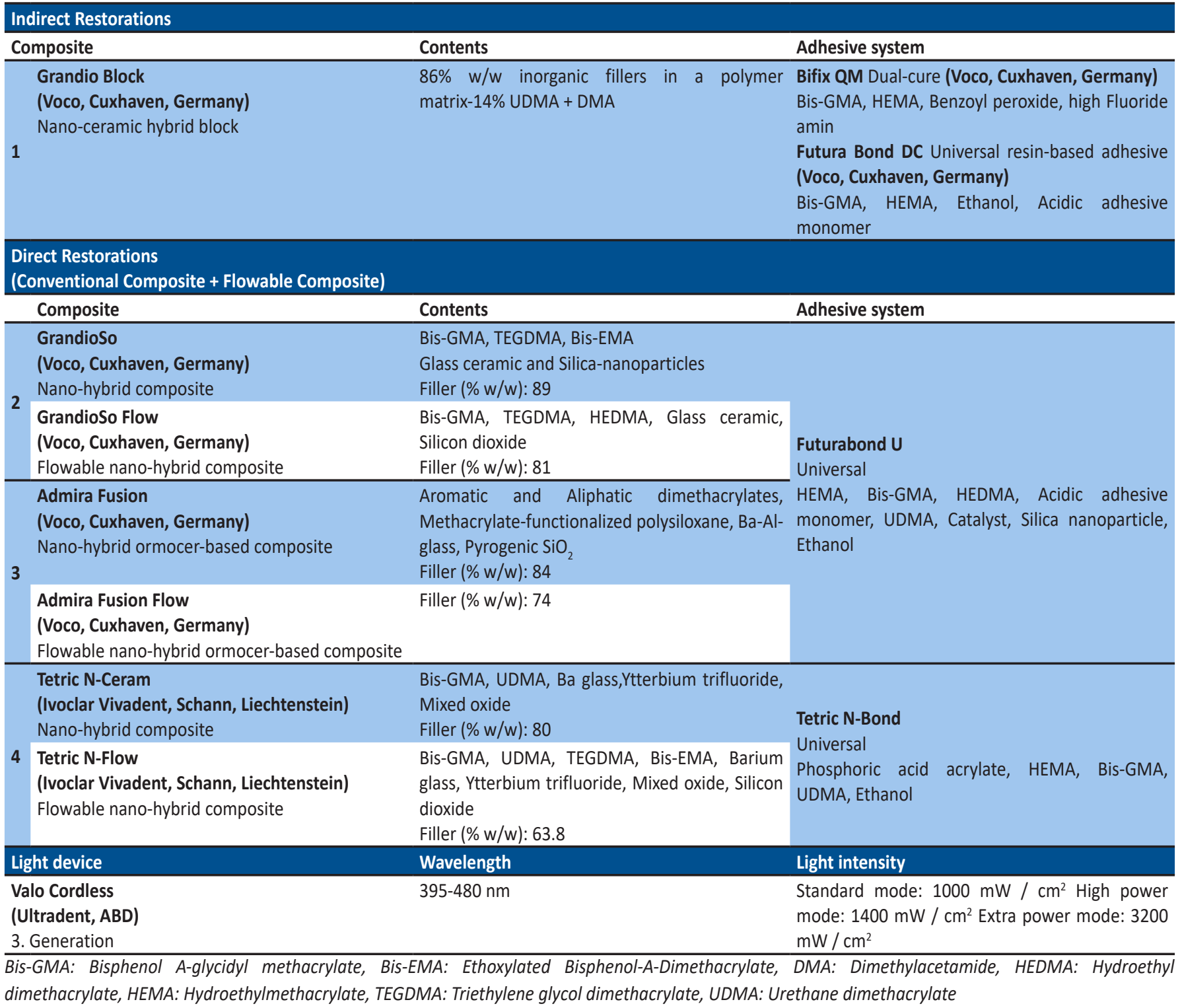

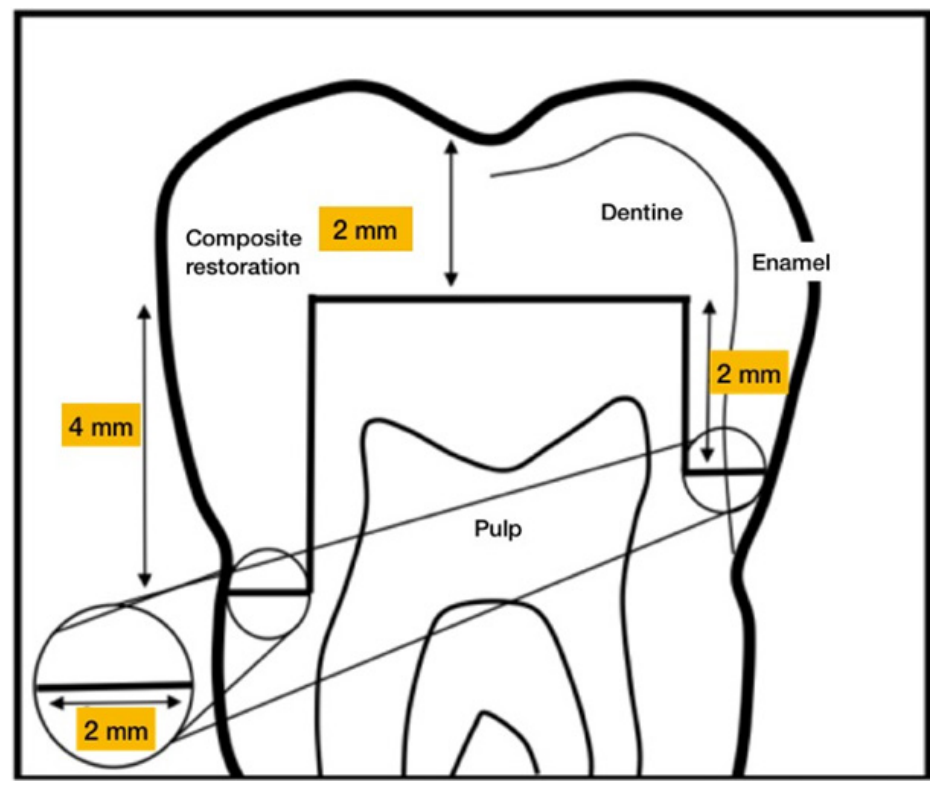

Figure 1. Measurements of Standard MOD Cavities 


\subsection{Indirect and Direct Composite Resin Restorations Procedure}

Indirect restorations were performed by using the CAD/CAM system (Sirona, Bensheim, Germany). After scanning the cavity margins of the teeth with the CEREC Omnicam camera, the restoration design was completed on the virtual model with the data obtained. Grandio blocks were placed in the processing unit (inLab MC X5) and processed according to the design. The materials (Table 1 ) and application methods used in the construction of indirect (Figure 2) and direct restorations (Figure 3 ) are described in Table 2.

Table 2. Indirect and Direct Composite Resin Restoration Procedure

\begin{tabular}{|c|c|c|c|c|}
\hline \multirow{5}{*}{ 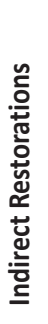 } & Restorative material & Acid & Adhesive system & Polisher \\
\hline & Grandio Block(GB) & Restoration surface: & Ceramic Bond was applied to the restoration surface for 60 & Dimanto (VOCO, \\
\hline & & $\begin{array}{l}\text { Porcelain Etch }(9 \% \text { HF }) \\
120 \mathrm{sec}\end{array}$ & $\begin{array}{l}\text { sec and waited and dried with air. Futurabond DC was applied } \\
\text { to both enamel-dentin and restoration surface for } 20 \mathrm{sec} \text {. The }\end{array}$ & Germany) \\
\hline & & Enamel surface: & indirect restorations were luted with Bifix QM Dual-cure, and & \\
\hline & & $\begin{array}{l}\left(35 \% \mathrm{H}_{3} \mathrm{PO}_{4}\right) \\
\text { Selective etch } 20 \mathrm{sec}\end{array}$ & & \\
\hline \multirow{13}{*}{ 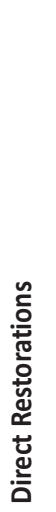 } & Restorative material & Acid & Adhesive system & Polisher \\
\hline & GrandioSo(G) & Enamel surface: & Futurabond $\mathbf{U}$ was applied to the enamel and dentine surface for & Dimanto (VOCO, \\
\hline & $2+2+1 \mathrm{~mm}$ layers & Vococid & $20 \mathrm{sec}$ and it was polymerized with Valo Cordless for $10 \mathrm{sec}$. & Germany) \\
\hline & GrandioSo Flow(GF) & $\left(35 \% \mathrm{H}_{3} \mathrm{PO}_{4}\right)$ & & \\
\hline & $1 \mathrm{~mm}$ layer-on the gingival seat & Selective etch $20 \mathrm{sec}$ & & \\
\hline & Admira Fusion(A) & Enamel surface: & Futurabond $U$ was applied to the enamel and dentine surface for & Dimanto (VOCO, \\
\hline & $2+2+1 \mathrm{~mm}$ layers & Vococid & $20 \mathrm{sec}$ and it was polymerized with Valo Cordless for $10 \mathrm{sec}$. & Germany) \\
\hline & Admira Fusion Flow(AF) & $\left(35 \% \mathrm{H}_{3} \mathrm{PO}_{4}\right)$ & & \\
\hline & $1 \mathrm{~mm}$ layer-on the gingival seat & Selective etch $20 \mathrm{sec}$ & & \\
\hline & Tetric N-Ceram(T) & Enamel surface: & Tetric N-Bond was applied to the enamel and dentine surface for & OptraPol (Ivoclar \\
\hline & $2+2+1 \mathrm{~mm}$ layers & N-Etch & $20 \mathrm{sec}$ and it was polymerized with Valo Cordless for $10 \mathrm{sec}$. & Vivadent, \\
\hline & Tetric N-Flow(TF) & $\left(37 \% \mathrm{H}_{3} \mathrm{PO}_{4}\right)$ & & Liechtenstein) \\
\hline & $1 \mathrm{~mm}$ layer-on the gingival seat & Selective etch $20 \mathrm{sec}$ & & \\
\hline
\end{tabular}
HF: Hydrofluoric acid, $\mathrm{H}_{3} \mathrm{PO}_{4}$ : Orthophosphoric acid

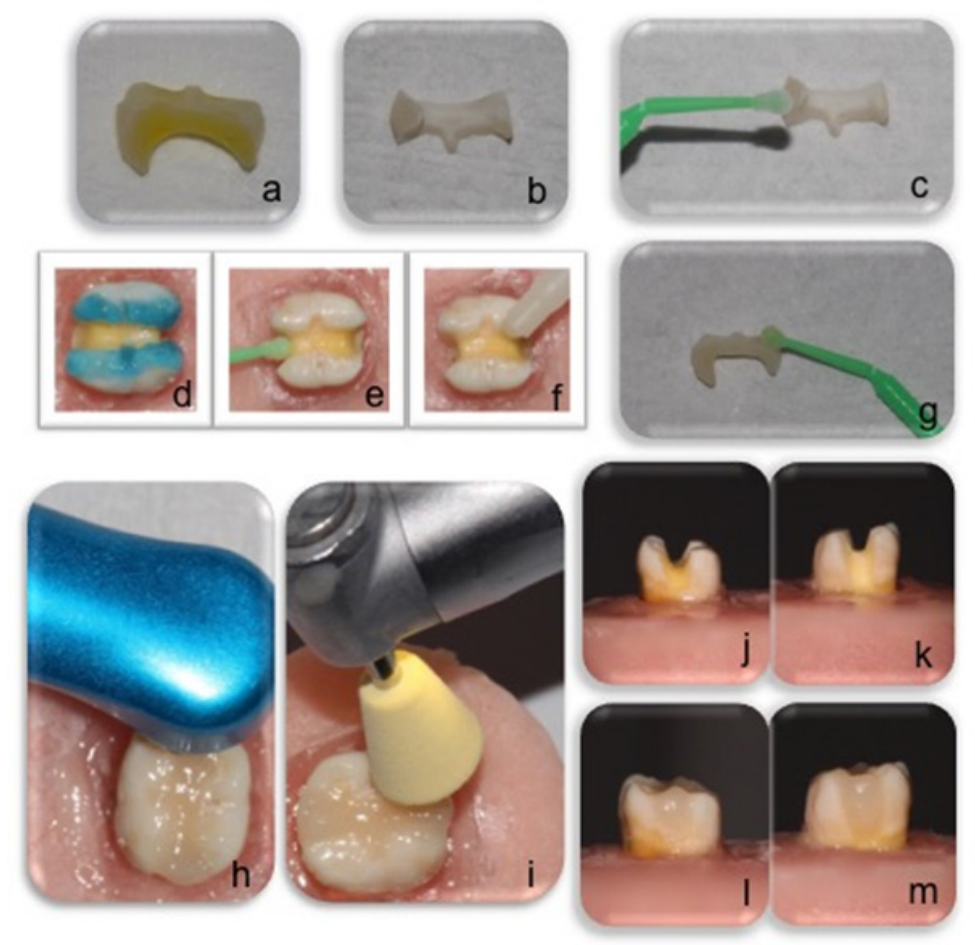

Figure 2. Indirect Composite Resin Restoration Procedure a. Etching the Restoration Surfaces with Hydrofluoric Acid, b. Restoration Surface After Etching, c. Silane Application, d. Selective Etching of the Enamel Surface, e. Bond Application on Enamel and Dentine Surfaces, f. Adhesive Resin Cement Application on Enamel and Dentine Surfaces, g. Bond Application on Restoration Surfaces, $\boldsymbol{h}$. Luting the Restoration to the Cavity with Adhesive Resin Cement and Polymerization, $\boldsymbol{i}$. Finishing and Polishing, j-k. Cavity Preparation of Indirect Restorations, I-m. Cavities Restored by Indirect Method. 


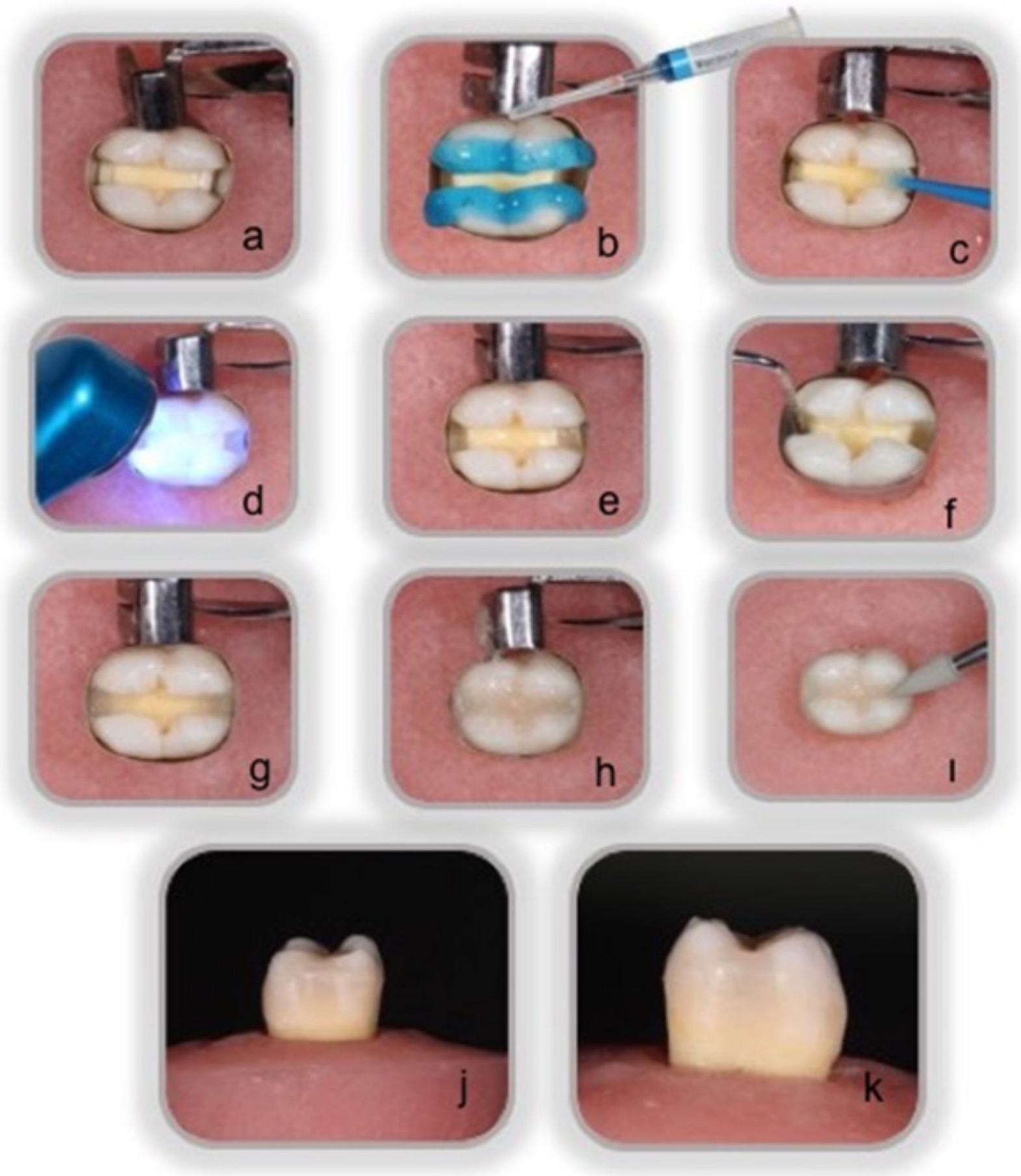

Figure 3. Direct Composite Resin Restoration Procedure a. Cavity Preparation of Direct Restorations, b. Selective Etching of the Enamel Surface, c. Bond Application on Enamel and Dentine Surfaces, d. Polymerization, e. $1 \mathrm{~mm}$ Flowable Composite Application on the Gingival Seat, $\boldsymbol{f}$. Measuring Material Thickness with a Periodontal Probe, $\boldsymbol{g}$-h. Restoration of the Cavity Using the Incremental Technique, $\boldsymbol{i}$. Finishing and Polishing, j-k. Cavities Restored by Direct Method.

\subsection{Thermo-Mechanical Loading}

The samples were subjected to thermomechanical fatigue using chewing simulator (Willytec SD Mechatronic $\mathrm{GmbH}$ CS-4.4 Professional Line, Feldkirchen-Westerham, Germany) (Figure 4). Thermo-mechanical loading was applied during cyclic loading to the restorations with a maximum occlusal load of $50 \mathrm{~N}$ at $1.7 \mathrm{~Hz}$. For simulating to standardized conditions steel balls of $6 \mathrm{~mm}$ in diameter acted as antagonists. 1-year clinical service stimulation was aimed with 240,000 loading cycles $(13,14)$. At the same time, thermal cycles were applied to the samples with a heated-cooled thermal cycle system controlled by PLCs included in the chewing simulator $\left(5^{\circ} \mathrm{C}\right.$ to $55^{\circ} \mathrm{C}$ every $\left.60 \mathrm{sec}\right)$. 


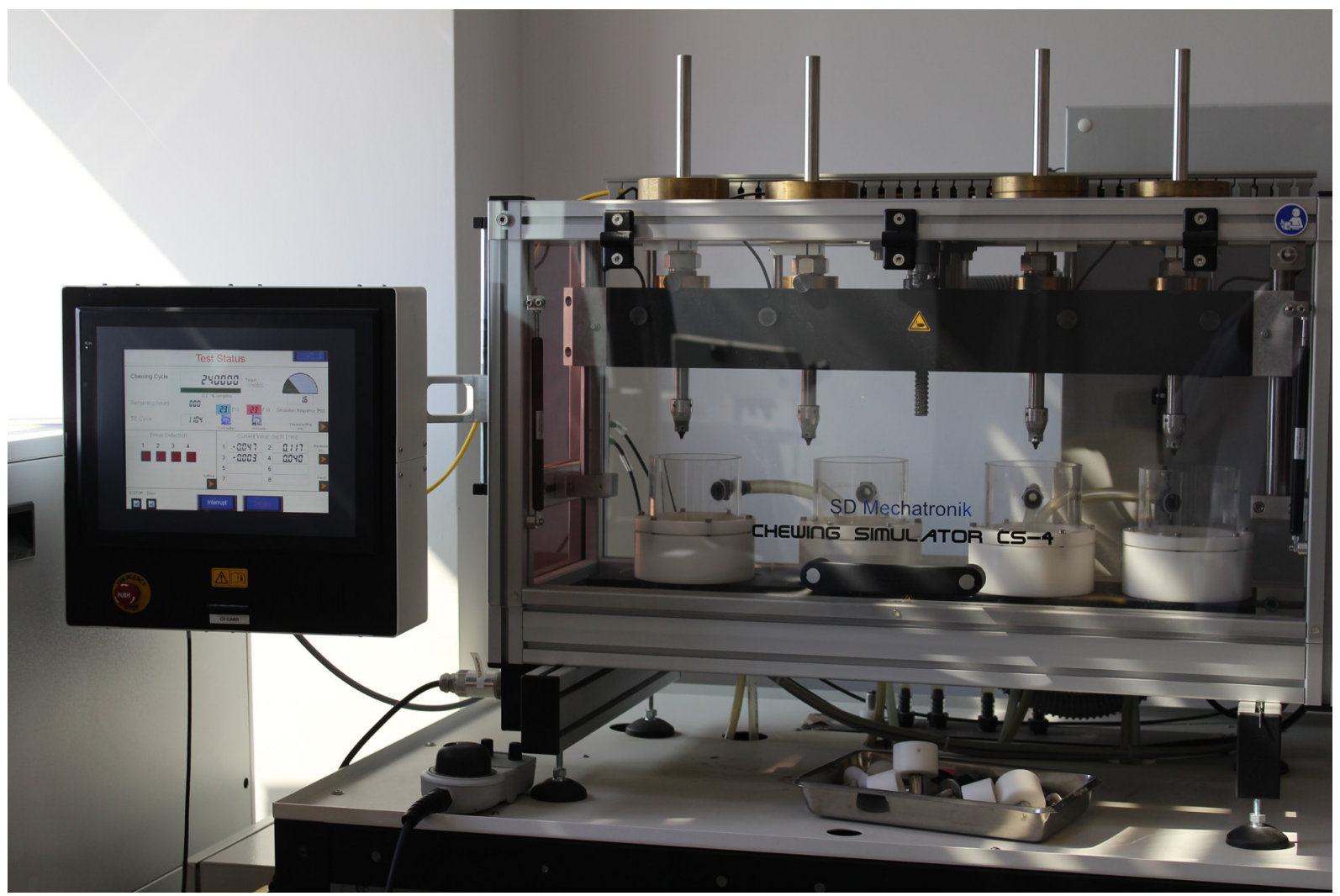

Figure 4. Chewing Simulator

\subsection{Evaluation of Microleakage and Marginal Adaptation}

After thermo-mechanical loading, all surfaces of the teeth samples were coated with nail polish except the restoration areas. Samples were kept in $0.2 \%$ methylene blue solution for 24 hours. The teeth were sectioned longitudinally in mesiodistal direction with a precision cutting device (IsoMet 1000, Buehler, USA). Coronal and gingival margin microleakage were scored under $\mathrm{X} 8$ and $\mathrm{X} 25$ magnifications using a lightstereomicroscope (Leica MZ 75, Germany) (Table 3) (15). The samples that were coated with gold/palladium (20\%/80\%) using Emitech SC7620 Sputter Coater were examined with Fei Sirion at $10 \mathrm{kV}$. The images of the samples examined by scanning electron microscopy under X120, X500, X5000 magnification were recorded.

Table 3. Scale Used to Evaluate Dye Penetration

\begin{tabular}{|c|c|}
\hline $\begin{array}{l}\text { Scoring for dye penetration for } \\
\text { marginal microleakage on the } \\
\text { cervical wall }\end{array}$ & $\begin{array}{l}\text { Scoring for dye penetration for } \\
\text { marginal microleakage on the } \\
\text { occlusal wall }\end{array}$ \\
\hline No dye penetration & 0. No dye penetration \\
\hline $\begin{array}{l}\text { 1. Dye penetration into half } \\
\text { extension of the cervical wall. }\end{array}$ & $\begin{array}{l}\text { 1. Dye penetration into half } \\
\text { extension. }\end{array}$ \\
\hline $\begin{array}{l}\text { Dye penetration into more } \\
\text { than half or complete } \\
\text { extension of the cervical wall. }\end{array}$ & $\begin{array}{l}\text { 2. Dye penetration more than } \\
\text { half. }\end{array}$ \\
\hline $\begin{array}{l}\text { 3. Dye penetration into the } \\
\text { cervical and axial walls towards } \\
\text { the pulp. }\end{array}$ & $\begin{array}{l}\text { 3. Dye penetration into the } \\
\text { pulpal wall. }\end{array}$ \\
\hline
\end{tabular}

\subsection{Statistical Analysis}

Statistical analyzes in this study were performed using the NCSS (Number Cruncher Statistical System) 2007 Statistical Software (Utah, USA) package program. In the evaluation of the data, descriptive statistical methods (frequency and percentage distributions) as well as the chi-square test was used for the comparison of qualitative data. The results were evaluated at the significance level of $p<0.05$.

\section{RESULTS}

\subsection{Microleakage Analysis}

The images obtained under $\mathrm{X} 8$ and $\mathrm{X} 25$ magnifications of samples with a gingival dye penetration score of 0 (Figure 5.a), 1 (Figure 5.b), 3 (Figure 5.c), and a coronal dye penetration score of 0 (Figure 5.b) were included.

No statistically significant difference was found among the coronal microleakage values of the $G+G F, A+A F, G B$, and $T+T F$ groups $(p=0.074)$. There was no statistically significant difference among the gingival-enamel microleakage values of the $G+G F, A+A F, G B$, and $T+T F$ groups ( $p=0.249$ ). A statistically significant difference was found among the gingival-cementum microleakage values of the $G+G F, A+A F$, $G B$, and T+TF groups ( $p=0.003$ ) (Table 4). 


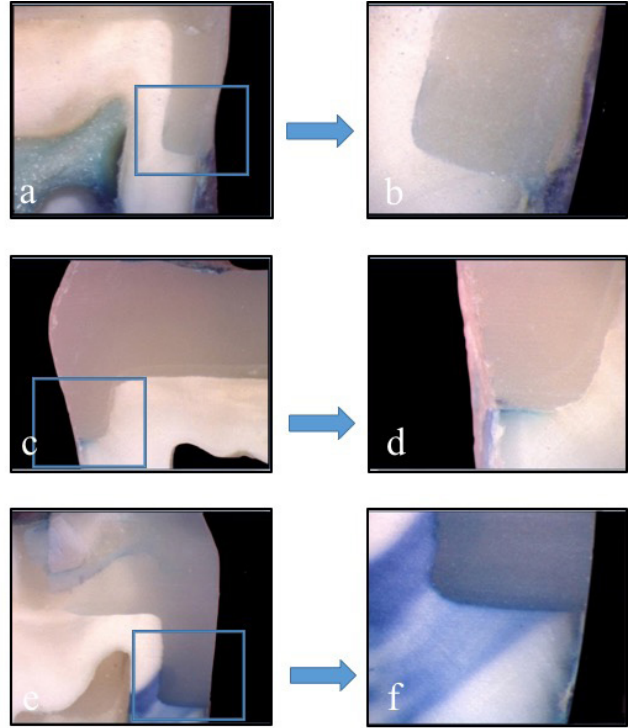

Figure 5. Dye Penetration According to Gingival and Coronal Score a. Dye Penetration Gingival Score $O(X 8), \boldsymbol{b}$. The Image of the Area Marked with a Rectangular Shape in Figure a, Recorded under X25 Magnification. $c$. Dye Penetration Gingival Score 1 and Dye Penetration Coronal Score $O(X 8), d$. The Image of the Area Marked with a Rectangular Shape in Figure $c$, Recorded under X25 Magnification. e. Dye Penetration Gingival Score 3 (X8), $f$. The Image of the Area Marked with a Rectangular Shape in Figure e, Recorded under X25 Magnification.

Table 4. Evaluation of Microleakage Scores According to Groups

\begin{tabular}{|c|c|c|c|c|c|c|}
\hline & & $\begin{array}{l}\text { G+GF } \\
N(\%)\end{array}$ & $\begin{array}{l}\text { A+AF } \\
N(\%)\end{array}$ & $\begin{array}{c}\text { GB } \\
\text { N (\%) }\end{array}$ & $\begin{array}{l}T+T F \\
N(\%)\end{array}$ & $\mathbf{p}$ \\
\hline \multirow{2}{*}{ 总 } & No dye penetration & $\begin{array}{ll}1 & 0 \\
(100)\end{array}$ & $9(90)$ & $5(55.56)$ & $8(80)$ & \multirow[b]{2}{*}{0.074} \\
\hline & $\begin{array}{l}\text { Dye penetration into } \\
\text { half extension }\end{array}$ & $0(0)$ & $1(10)$ & $4(44.44)$ & $2(20)$ & \\
\hline \multirow{4}{*}{ 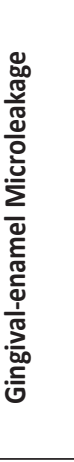 } & No dye penetration & $7(70)$ & 7 (70) & $5(55.56)$ & $4(40)$ & \multirow{4}{*}{0.249} \\
\hline & $\begin{array}{l}\text { Dye penetration into } \\
\text { half extension of the } \\
\text { cervical wall }\end{array}$ & $3(30)$ & $2(20)$ & $2(22.2)$ & $5(50)$ & \\
\hline & $\begin{array}{l}\text { Dye penetration into } \\
\text { more than half or } \\
\text { complete extension } \\
\text { of the cervical wall }\end{array}$ & $0(0)$ & $1(10)$ & $0(0)$ & $1(10)$ & \\
\hline & $\begin{array}{l}\text { Dye penetration into } \\
\text { the cervical and axial } \\
\text { walls towards the } \\
\text { pulp }\end{array}$ & $0(0)$ & $0(0)$ & $2(22.22)$ & $0(0)$ & \\
\hline \multirow{4}{*}{ 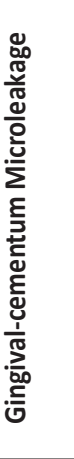 } & No dye penetration & $6(60)$ & $3(30)$ & 5 (55.56) & $0(0)$ & \multirow{4}{*}{0.003} \\
\hline & $\begin{array}{l}\text { Dye penetration into } \\
\text { half extension of the } \\
\text { cervical wall }\end{array}$ & $3(30)$ & $3(30)$ & $1(11.11)$ & $5(50)$ & \\
\hline & $\begin{array}{l}\text { Dye penetration into } \\
\text { more than half or } \\
\text { complete extension } \\
\text { of the cervical wall }\end{array}$ & 1 (10) & $4(40)$ & $0(0)$ & $5(50)$ & \\
\hline & $\begin{array}{l}\text { Dye penetration into } \\
\text { the cervical and axial } \\
\text { walls towards the } \\
\text { pulp }\end{array}$ & $0(0)$ & $0(0)$ & $3(33.33)$ & $0(0)$ & \\
\hline
\end{tabular}

A+AF:Admira Fusion+Admira Fusion Flow, G+GF:GrandioSo+GrandioSo Flow, GB:GrandioBlock, T+TF:Tetric N-Ceram+Tetric N-Flow
Among the $T+T F, G+G F$, and GB groups, the distributions of gingivalcement microleakage no dye penetration were statistically significantly lower in the T+TF group $(p=0.010, p=0.001)$. The gingival-cementum microleakage score 3 distributions of the GB group were found to be statistically significantly higher than the $A+A F$ group ( $p=0.037)$. No statistically significant difference was found among the gingival-cementum microleakage distributions of the other groups ( $p>0.05$ ) (Table 5).

Table 5. Comparison of Microleakage Values According to Groups

\begin{tabular}{|c|c|c|c|}
\hline & $\begin{array}{c}\text { Coronal } \\
\text { Microleakage }\end{array}$ & $\begin{array}{c}\text { Gingival-enamel } \\
\text { Microleakage }\end{array}$ & $\begin{array}{c}\text { Gingival-cementum } \\
\text { Microleakage }\end{array}$ \\
\hline G+GF / A+AF & 0.304 & 0.549 & 0.246 \\
\hline G+GF / GB & 0.051 & 0.288 & 0.168 \\
\hline G+GF / T+TF & 0.136 & 0.313 & $\mathbf{0 . 0 1 0}$ \\
\hline A+AF / GB & 0.140 & 0.349 & $\mathbf{0 . 0 3 7}$ \\
\hline A+AF / T+TF & 0.531 & 0.701 & 0.164 \\
\hline GB / T+TF & 0.252 & 0.226 & $\mathbf{0 . 0 0 1}$ \\
\hline
\end{tabular}

A+AF:Admira Fusion+Admira Fusion Flow, G+GF:GrandioSo+GrandioSo Flow, GB:GrandioBlock, T+TF:Tetric N-Ceram+Tetric N-Flow

\subsection{SEM Images}

In our study in which two samples of each group were evaluated with SEM, the gap formation observed in the SEM evaluation of the GB group occurred between both dentine-cement material, and the block-cement material (Figure 6.a). According to the result obtained from SEM evaluations, gap formation between dentine and adhesive layer was observed in $T+T F$ and $A+A F$ groups (Figure 6.b and c). Gap formation observed in the sample taken from the G+GF group was less common (Figure 6.d).

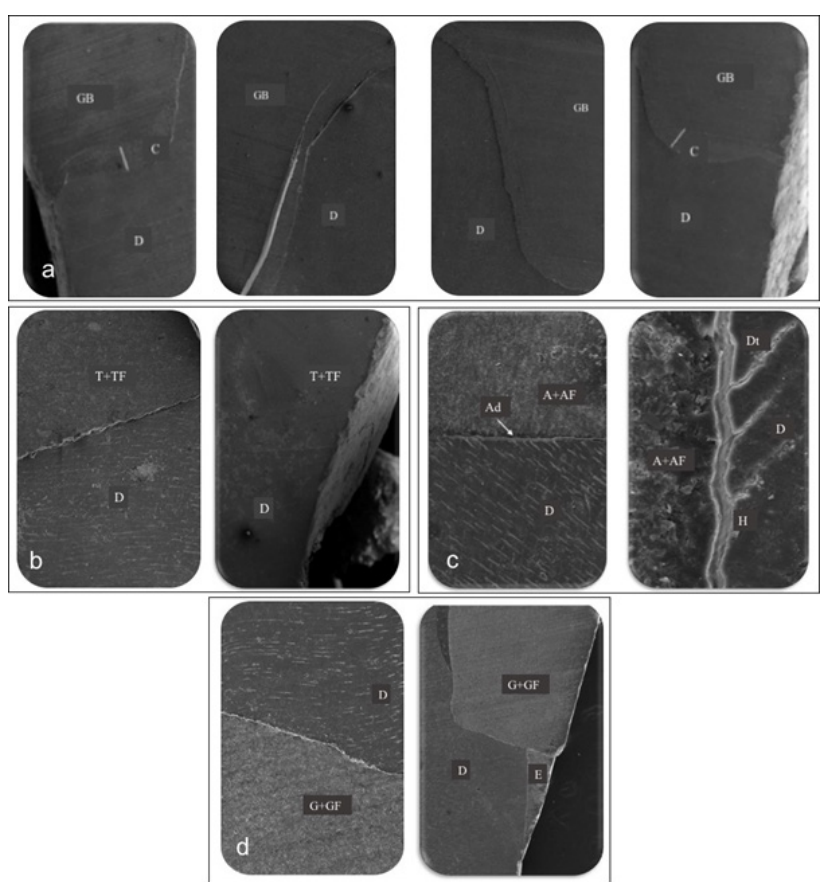

Figure 6. SEM Images a. GB X120 and X500 SEM Image (D:Dentine and C:Cementum), b. T+TF X120 and X500 SEM Image (D:Dentine), c. A+AF X500 and X5000 SEM Image (D:Dentine, Ad:Adhesive, H:Hybrid Layer and Dt:Dentine Tubules), d. G+GF X120 and X500 SEM Image (D:Dentine and E:Enamel) 


\section{DISCUSSION}

Disadvantages of composites such as polymerization shrinkage, shrinkage stress, insufficient cavity adaptation, and microleakage have led to new pursuits in the development of composite materials. Ormocer-based composites with differences in the chemical structures have been produced to prevent clinical failure and to extend the survival of the restoration (16).

It is aimed to make restorations with low polymerization shrinkage, high abrasion resistance, and biocompatibility by increasing the amount of silicon in the filler content in composites that are ormocer-based and produced by modifying the organic phase. The specific oligomers of ormocer materials can be obtained by hydrolyzing and densifying the silane molecules used to functionalize the surface of fillers in conventional resin composites (6). If the oligomers have suitable viscosity and hydrophilicity, they can form the entire resin phase if the filler allows particle loading, thus replacing Bis-GMA, TEGDMA, and other conventional dimethacrylates (17).

In our study, no statistically significant difference was found between the coronal and gingival-enamel microleakage values of the ormocer-based nano-hybrid composite and other composite groups. In cavities that ended beyond the cementoenamel junction, the A+AF group has a lower gingival-cementum microleakage score compared to the $\mathrm{T}+\mathrm{TF}$ and $\mathrm{GB}$ groups.

There are studies comparing ormocer-based composites with different restorative materials in terms of microleakage. In the study of Garapati et al., class II cavities were restored with nanofill composite (Filtek supreme), ormocer-based composite (Admira), and micro-hybrid composite (P60) were compared and no significant difference was found between the groups (18). Hodobet et al., in their study, compared the marginal adaptation of the restoration to the cavity with SEM in class II cavities restored with ormocer (Admira Fusion), nanocomposite (Premise), micro-hybrid composite (Gradia Direct). It was found that there were no significant differences between the materials used in both dentine and cementum (19). Kalra et al., compared the microleakage values after thermal cycle in class I restorations of ormocerbased (Admira) and hybrid composites (TPH Spectrum) using ormocer-based adhesive and universal 5th generation adhesive. The low dye penetration scores were obtained in the restoration of the ormocer-based composite with ormocer-based adhesive. However, no statistically significant difference was found (20). This finding is consistent with the studies by Fleming et al., Hodobet et al., and Garapati et al., which did report no significant difference in dye penetration among different materials $(18,21)$.

In a study by Politi et al., compared the microleakage values after the thermo-mechanical cycle of class II restorations using ormocer-based composite (Admira Fusion) and methacrylate-based composite (Tetric EvoCeram), the ormocer group has lower microleakage values compared to the methacrylate group (22). In the study of Yazıcı et al., after thermo-mechanical loading, there is no statistical difference between occlusal and gingival microleakage scores in all restorative material groups. It is noteworthy that there is no occlusal and gingival micro-leakage in the class $v$ cavity group restoring with ormocer-based composite. This is attributed to the fact that ormocer has less polymerization shrinkage due to its organic resin structure (23).

In our study, the higher number of samples with no dye penetration in the G+GF group compared to the $A+A F$ group was associated with the high percentage of filler content of GF causing less polymerization shrinkage. The different results obtained from the studies can be explained by the different methods followed in the study. While the aging method with the thermal cycle is frequently used in the studies performed, aging with the thermo-mechanical cycle, which is thought to simulate the oral environment was preferred in our study.

Restorations in the oral environment are exposed to thermal changes and different $\mathrm{pH}$ values with the intake of food and liquids at various temperatures during the day. Thermal changes can result in gaps and microleakage due to the inconsistency in the thermal expansion coefficient between the restorative material and dental tissue and the stress it creates (13). Vertical occlusal loads that occur between the opposing teeth during the chewing of food cause the stresses that occur by transmitting to the occlusal surfaces of the teeth to spread to all occlusal surfaces. All these occlusal loads affect the long-term success of the restorations by mechanically destroying the bonds at the adhesive interface. For this reason, aging tests such as thermal cycle and mechanical loading are used to imitate the oral environment in vitro studies where materials are evaluated $(13,16)$. In our study, 1-year clinical aging was aimed at applying mechanical loading at 240,000 cycles with $50 \mathrm{~N}$ force (24).

One of the most important features aimed in successful restorations is to provide ideal marginal adaptation to prevent clinical consequences such as microleakage, marginal discoloration, secondary caries, and sensitivity. Despite the ongoing development of resin composites, the marginal leakage encountered may be related to insufficient bonding between the adhesive material and tooth structures such as cementum and dentine layer or non-prism enamel tissue. Numerous studies have shown that the restorative material does not provide good marginal adaptation in the restoration of cavities terminating below the cementoenamel junction, compared to restorations that end in enamel, and that low marginal closure leads to an increase in gingival microleakage $(16,25,26)$. Bonding of resin with enamel is mainly micromechanical and is based on obtaining a high energy roughened surface that can be wetted with low viscosity adhesive agents for resin tag formation. Surface preparation in dentin tissue is important for forming a hybrid layer where a hydrophilic monomer can penetrate and attached with the exposed collagen to provide micro-mechanical connection (27). Dentin tissue, which has low mineral content compared to enamel, has a complex structure rich in organic molecules. 
Increased microleakage values in the area under the CEJ were associated with larger diameter and a great number of dentinal tubules compared to the occlusal wall (28).

In our study, microleakage values were compared in cavities ending in cementum and enamel tissues and no statistically significant difference was found. When the scores are examined, microleakage values increased for all composite groups in cavities ending under the cementoenamel junction.

Based on the results of the studies conducted, low-viscosity composite applications are recommended in order to reduce the microleakage that may occur in this area $(29,30)$. In class II cavities, it was aimed to increase marginal adaptation and marginal sealing, decrease dentin sensitivity and create a stress-breaking layer with the application of flowable resin composites in deep, hard-to-reach areas below the CEJ (29). In the restorations of the teeth divided into groups in this study, flowable composites were used as liner materials. Ormocer-based and methacrylate-based composites were preferred as flowable composite materials.

In our study, the number of samples with gingival-cementum no dye penetration score was found to be statistically significantly lower in the T+TF group than in the G+GF and $\mathrm{GB}$ groups. The gingival-cementum microleakage scores were higher in the T+TF group compared to the G+GF group. In the study where both groups have nano-hybrid composite properties, different leakage values can be explained with different filler ratios, the size of the filler particles, the monomer composition with organic content, and two different ethanol-based adhesive agents used in adhesion. According to the results we obtained from our study; the second null hypothesis was partially rejected.

Increasing the inorganic content of composites and adding pre-polymerized resin fillers (organic fillers) restricts polymerization shrinkage by reducing the amount of monomer. This can also increase the elastic modulus of the material and lead to high shrinkage stress (31). Polymerization shrinkage stresses are affected by the composition, filler content, elastic modulus, and viscosity of the resin composite and these properties can compensate for the stresses generated during polymerization. As a reflection of these properties, the degree of polymerization conversion and polymerization depth influence the stress formation by affecting the quality of the bond at the interface of the restorations $(32,33)$.

There is a correlation between the shrinkage stress values of composites and internal adaptation $(34,35)$. While a high polymerization rate can be observed in the upper layer of the composite materials applied to the cavity and the surfaces connected to the outer walls of the cavity close to the light source, a low polymerization rate can be achieved in the inner and pulpal walls. As a result of polymerization shrinkage, stress flow between these areas and gaps in the marginal surface may occur $(35,36)$. Inadequate adaptation with the dentin surface of the material is an indication of the increased potential for gap formation and microleakage (37).
Because CAD / CAM blocks can be produced under controlled conditions, their physical and optical properties are higher than traditional indirect restorations. Marginal integrity, cavity preparation design, and cementation are factors that determine the long-term clinical success of indirect restorations (9).

Different parameters can affect the adaptation of CAD/CAM inlay/onlay restorations. The type of processing device, the design of the restoration, its interior angles, and groove areas are influential on the adaptation of the restoration to the cavity. Preparation of the cavity and its complex geometry is important for the accuracy of intraoral scanning $(38,39)$.

For indirect composite restorations, polymerization shrinkage is limited to the adhesive cement material. It has been shown that adhesive cement thickness has a statistically significant effect on marginal adaptation of CAD/CAM restorations. As the cement thickness decreased, the marginal fit increased $(40,41)$.

In the study of Qian et al., where marginal adaptation and marginal gaps were evaluated under stereomicroscope, samples were restored with CAD/CAM blocks (Enamic, Lava Ultimate) and lab composite (Ceramage). Digital intraoral impression and CAD/CAM systems have not shown superior accuracy in obtaining hybrid ceramic inlays compared to conventional technique. All of the overall mean marginal gaps of inlay restorations made with hybrid ceramics were obtained within the clinically acceptable range (42).

Grandio block was preferred in our study due to the limited literature on nano-hybrid ceramic CAD/CAM blocks.

In the study of Bortolotto et al., the marginal adaptation of CEREC ceramic inlays, CEREC composite inlays, and direct composite restorations in proximal slot cavities was evaluated using scanning electron microscopy. It is concluded that the marginal adaptation of indirect restorations made of both composite and ceramic is better than direct composite restorations (43).

In our study, no significant difference was found between the coronal and gingival-enamel microleakage values of restorations made with CAD/CAM blocks and G+GF group direct restorations.

When the gingival-cementum microleakage values of $G B$ and $A+A F$ groups are compared, the fact that the GB group does not have lower microleakage scores. It can be attributed to the fact that the block is not included in the software program used, and the data was entered by selecting the same size but the different block to transfer it to the processing device. This situation is thought to negatively affect the adaptation of the restoration to the cavity and shows the importance of the design program and the processing device. So first null hypothesis was partially rejected.

The limitations of our in-vitro study, in which the microleakage scores were compared by aging the restorations with a chewing simulator, are the lack of factors such as saliva, patient's diet, and oral hygiene habits that affect the natural 
conditions in the oral cavity. Further limiting factor may be steel antagonist ball used instead of human tooth as antagonist in chewing simulator.

\section{CONCLUSIONS}

When the data we obtained within the limitations of this study are evaluated, we can reach the following results:

1. Different application techniques and materials used in the present study, could not completely eliminate the microleakage observed at the tooth-restoration interfaces.

2. A higher microleakage value was obtained in the restorations of the prepared MOD cavities ending in cementum compared to the restorations ending in enamel.

3. Microleakage values in indirect restorations obtained with CAD/CAM block showed similar results with direct restorations.

Under the conditions of this study, the use of conventional nanocomposite in the direct restoration of MOD cavities has shown the least microleakage.

Today, limited information about the content and structure of ormocer materials can be reached. The limited number of clinical and in vitro studies carried out requires more studies in order to reach clear information about the clinical longevity and success rate of the ormocers.

\section{Funding}

There was no grant support or research funding for this article.

\section{Conflict of Interests}

The authors do not have any financial interest in the companies whose materials are included in this article.

\section{REFERENCES}

[1] Ástvaldsdóttir Á, Dagerhamn J, van Dijken JW, Naimi-Akbar A, Sandborgh-Englund G, Tranæus S, Nilsson M. Longevity of posterior resin composite restorations in adults - A systematic review. J Dent 2015;43(8):934-954.

[2] Moraschini V, Fai CK, Alto RM, Dos Santos GO. Amalgam and resin composite longevity of posterior restorations: A systematic review and meta-analysis. J Dent 2015;43(9):10431050.

[3] Kruly PC, Giannini M, Pascotto RC, Tokubo LM, Suga USG, Marques ACR, Terada RSS. Meta-analysis of the clinical behavior of posterior direct resin restorations: Low polymerization shrinkage resin in comparison to methacrylate composite resin. PLoS One 2018;13(2):e0191942.

[4] Reddy SN, Jayashankar DN, Nainan M, Shivanna V. The effect of flowable composite lining thickness with various curing techniques on microleakage in class II composite restorations: an in vitro study. J Contemp Dent Pract 2013;14(1):56-60.

[5] Lokhande NA, Padmai AS, Rathore VP, Shingane S, Jayashankar DN, Sharma U. Effectiveness of flowable resin composite in reducing microleakage - an in vitro study. J Int Oral Health 2014;6(3):111-114.

[6] Randolph LD, Palin WM, Leprince JG. Composition of dental resin-based composites for direct restorations. In: Miletic V, Eds. Dental Composite Materials for Direct Restorations. Belgrade: Springer International Publishing; 2018.p.11-24.

[7] Stawarczyk B, Liebermann A, Eichberger M, Güth JF. Evaluation of mechanical and optical behavior of current esthetic dental restorative CAD/CAM composites. J Mech Behav Biomed Mater 2015;55:1-11.

[8] Wendler M, Belli R, Petschelt A, Mevec D, Harrer W, Lube T, Danzer R, Lohbauer U. Chairside CAD/CAM materials. Part 2: Flexural strength testing. Dent Mater 2017;33(1):99-109.

[9] Park SH, Yoo YJ, Shin YJ, Cho BH, Baek SH. Marginal and internal fit of nano-composite CAD/CAM restorations. Restor Dent Endod 2016;41(1):37-43.

[10] Opdam N, Frankenberger R, Magne P. From 'Direct versus indirect' toward an integrated restorative concept in the posterior dentition. Oper Dent 2016;41(S7):27-34.

[11] Hickel R, Peschke A, Tyas M, Mjör I, Bayne S, Peters M, Hiller KA, Randall R, Vanherle G, Heintze SD. FDI World Dental Federation - clinical criteria for the evaluation of direct and indirect restorations. Update and clinical examples. J Adhes Dent 2010;12(4):259-272.

[12] Manhart J, Chen H, Hamm G, Hickel R. Buonocore Memorial Lecture. Review of the clinical survival of direct and indirect restorations in posterior teeth of the permanent dentition. Oper Dent 2004;29(5):481-508.

[13] Yılmaz EC, Sadeler R. Investigation of three-body wear of dental materials under different chewing cycles. Sci Eng of Compos Mater 2018;25(4):781-787.

[14] Kayali F, Kahramanoglu E. Comparison of fracture resistance between two monolithic and one veneered zirconia materials on molar crowns after thermomechanical fatigue. Clin Exp Health Sci 2020;10:320-326.

[15] Swapna MU, Koshy S, Kumar A, Nanjappa N, Benjamin S, Nainan MT. Comparing marginal microleakage of three bulk fill composites in class II cavities using confocal microscope: An in vitro study. J Conserv Dent 2015;18(5):409-413.

[16] Erdilek D, Dörter C, Koray F, Kunzelmann KH, Efes BG, Gomec $Y$. Effect of thermo-mechanical load cycling on microleakage in class II ormocer restorations. Eur J Dent 2009;3(3):200-205.

[17] Moszner N, Völkel T, Cramer von Clausbruch S, Geiter E, Batliner $\mathrm{N}$, Rheinberger V. Synthesis and hydrolytic condensation of new cross-linking alkoxysilane methacrylates and light-curing composites based upon the condensates. Macromol Mater Eng 2002;287(5):339-347.

[18] Garapati S, Das M, Mujeeb A, Dey S, Kiswe SP. Cuspal movement and microleakage in premolar teeth restored with posterior restorative materials. J Int Oral Health 2014;6(5):4750.

[19] Hodobet C, Pangica AM, Florescu A, Hancu V, Biclesanu CF. In vitro Comparative study on the marginal adaptation of direct, semi-direct and indirect composite resins restorations to dentine and dental cementum. Revista de Chimie 2018;69:3138-3145. 
[20] Kalra S, Singh A, Gupta M, Chadha V. Ormocer: An aesthetic direct restorative material; An in vitro study comparing the marginal sealing ability of organically modified ceramics and a hybrid composite using an ormocer-based bonding agent and a conventional fifth-generation bonding agent. Contemp Clin Dent 2012;3(1):48-53.

[21] Fleming GJ, Hall DP, Shortall AC, Burke FJ. Cuspal movement and microleakage in premolar teeth restored with posterior filling materials of varying reported volumetric shrinkage values. J Dent 2005;33(2):139-146.

[22] Politi I, McHugh LEJ, Al-Fodeh RS, Fleming GJP. Modification of the restoration protocol for resin-based composite (RBC) restoratives (conventional and bulk fill) on cuspal movement and microleakage score in molar teeth. Dent Mater 2018;34(9):1271-1277.

[23] Yazici AR, Celik C, Ozgünaltay G. Microleakage of different resin composite types. Quintessence Int 2004;35(10):790-794.

[24] Habib SR, Alotaibi A, Al Hazza N, Allam Y, AlGhazi M. Two-body wear behavior of human enamel versus monolithic zirconia, lithium disilicate, ceramometal and composite resin. J Adv Prosthodont 2019;11(1):23-31.

[25] Takahashi R, Nikaido T, Tagami J, Hickel R, Kunzelmann $\mathrm{KH}$. Contemporary adhesives: Marginal adaptation and microtensile bond strength of class II composite restorations. Am J Dent 2012;25(3):181-188.

[26] Gamarra VSS, Borges GA, Júnior LHB, Spohr AM. Marginal adaptation and microleakage of a bulk-fill composite resin photopolymerized with different techniques. Odontology 2018;106(1):56-63.

[27] Nakabayashi N, Ashizawa M, Nakamura M. Identification of a resin-dentin hybrid layer in vital human dentin created in vivo: durable bonding to vital dentin. Quintessence Int 1992;23(2):135-141.

[28] Pongprueksa P, Senawongse P, Vongphan N. Effect of dentinal tubule orientation on the modulus of elasticity of resininfiltrated demineralized dentin. Dent Mater J 2014;33(1):5458.

[29] Nie J, Yap AU, Wang XY. Influence of shrinkage and viscosity of flowable composite liners on cervical microleakage of class II restorations: a micro-ct analysis. Oper Dent 2018;43(6):656664.

[30] Kitayama S, Nasser NA, Pilecki P, Wilson RF, Nikaido T, Tagami J, Watson TF, Foxton RM. Effect of resin coating and occlusal loading on microleakage of class II computer-aided design/computer-aided manufacturing fabricated ceramic restorations: a confocal microscopic study. Acta Odontol Scand 2011;69(3):182-192.
[31] Al Sunbul H, Silikas N, Watts DC. Polymerization shrinkage kinetics and shrinkage-stress in dental resin-composites. Dent Mater 2016;32(8):998-1006.

[32] Boaro LC, Gonçalves F, Guimarães TC, Ferracane JL, Versluis A, Braga RR. Polymerization stress, shrinkage and elastic modulus of current low-shrinkage restorative composites. Dent Mater 2010;26(12):1144-1150.

[33] Van Ende A, De Munck J, Mine A, Lambrechts P, Van Meerbeek B. Does a low-shrinking composite induce less stress at the adhesive interface? Dent Mater 2010;26(3):215-222.

[34] Han SH, Sadr A, Tagami J, Park SH. Internal adaptation of resin composites at two configurations: Influence of polymerization shrinkage and stress. Dent Mater 2016;32(9):1085-1094.

[35] Fronza BM, Rueggeberg FA, Braga RR, Mogilevych B, Soares LE, Martin AA, Ambrosano G, Giannini M. Monomer conversion, microhardness, internal marginal adaptation, and shrinkage stress of bulk-fill resin composites. Dent Mater 2015;31(12):1542-1551.

[36] Soares GP, Ambrosano GM, Lima DA, Marchi GM, CorrerSobrinho L, Lovadino JR, Aguiar FH. Effect of light polymerization time, mode, and thermal and mechanical load cycling on microleakage in resin composite restorations. Lasers Med Sci 2014;29(2):545-550.

[37] Agarwal RS, Hiremath H, Agarwal J, Garg A. Evaluation of cervical marginal and internal adaptation using newer bulk fill composites: An in vitro study. J Conserv Dent 2015;18(1):5661.

[38] Kirsch C, Ender A, Attin T, Mehl A. Trueness of four different milling procedures used in dental CAD/CAM systems. Clin Oral Investig 2017;21(2):551-558.

[39] Alghazzawi TF. Advancements in CAD/CAM technology: Options for practical implementation. J Prosthodont Res 2016;60(2):72-84.

[40] Sandoval MJ, Rocca GT, Krejci I, Mandikos M, Dietschi D. In vitro evaluation of marginal and internal adaptation of class II CAD/CAM ceramic restorations with different resinous bases and interface treatments. Clin Oral Investig 2015;19(9):21672177.

[41] Shim JS, Lee JS, Lee JY, Choi YJ, Shin SW, Ryu JJ. Effect of software version and parameter settings on the marginal and internal adaptation of crowns fabricated with the CAD/CAM system. J Appl Oral Sci 2015;23(5):515-522.

[42] Qian K, Yang X, Feng H, Liu Y. Marginal adaptation of different hybrid ceramic inlays after thermal cycling. Adv Appl Ceram 2020;119(5-6):284-290.

[43] Bortolotto T, Onisor I, Krejci I. Proximal direct composite restorations and chairside CAD/CAM inlays: Marginal adaptation of a two-step self-etch adhesive with and without selective enamel conditioning. Clin Oral Investig 2007;11(1):35-43.

How to cite this article: Senol AA, Atali PY, Kahramanoglu E. Microleakage and Marginal Integrity of Direct and Indirect Composite Resin Restorations in MOD Cavities After Thermo-Mechanical Loading. Clin Exp Health Sci 2021; 11: 564-574. DOI: 10.33808/ clinexphealthsci.880368 